\title{
Antimicrobial Susceptibility of Metallo-beta-Lactamase Positive and Negative Klebsiella pneumoniae Strains Isolated from Intensive Care Unit Patients
}

\author{
ALICJA SĘKOWSKA ${ }^{1 *}$, WALERIA HRYNIEWICZ², MAREK GNIADKOWSKI ${ }^{2}$, \\ ALEKSANDER DEPTUŁA ${ }^{1}$, KRZYSZTOF KUSZA $^{3}$, EUGENIA GOSPODAREK ${ }^{1}$

\footnotetext{
${ }^{1}$ Department of Microbiology, Nicolas Copernicus University, Collegium Medicum in Bydgoszcz, Poland ${ }^{3}$ Department of Anesthesiology and Intensive Care Nicolas Copernicus University, Collegium Medicum in Bydgoszcz, Poland
} \\ ${ }^{2}$ National Medicines Institute, Division of Clinical Microbiology and Infection Prevention in Warsaw, Poland
}

Received 16 April 2009, revised 15 January 2010, accepted 20 January 2010

\begin{abstract}
Carbapenem resistance in Gram-negative bacteria is a worldwide increasing and one of the most disturbing problems, given these antibiotics are drugs of choice in the treatment of infections caused by extended-spectrum-beta-lactamase producing strains. In this study the antibiotic susceptibility of metallo-beta-lactamase-positive and negative Klebsiella pneumoniae strains isolated from intensive care unit (ICU) patients was evaluated. The presence of genes encoding MBLs was determined with a commercial kit hyplex® MBL ID (BAG HEALTH CARE). The MBL-producing isolates were the first K.pneumoniae isolates of this kind identified in Poland. It seems that methods for detecting MBLs in Enterobacteriaceae should be included in contemporary standards of microbiological diagnostics in the country.
\end{abstract}

K e y w ord s: Klebsiella pneumoniae, hospital acquired infection, Hyplex MBL-ID, metallo-beta-lactamase

Carbapenems are the drugs of choice in the treatment of infections caused by extended-spectrum betalactamase (ESBL)-positive strains which are resistant to all penicillins, cephalosporins and monobactams (Livermore, 2008). ESBL-producing strains causing hospital-acquired infections are a serious therapeutical and epidemiological problem, especially in ICU patients who are of high risk for infections caused by multidrug-resistant bacterial strains. Klebsiella pneumoniae are one of the most frequently isolated pathogens from ICU patients (Rudnicka et al., 2005), and one of the most frequent ESBL producers, including Poland (Empel et al., 2008). Recently, an even more disturbing problem has emerged, which is the growing number of reports on metallo-beta-lactamase (MBL)positive Enterobacteriaceae strains, which follow the Gram-negative non-fermenters (Watanabe et al., 1991; Giakkoupi et al., 2003, Luzzaro et al., 2004, Pournaras et al., 2005). MBLs hydrolyze penicillins, cephalosporins and carbapenems and are not inhibited by beta-lactamase inhibitors (Walsh et al., 2005; Queenan and Bush, 2007).
The aim of this study was to evaluate the antimicrobial susceptibility of $25 \mathrm{~K}$. pneumoniae strains isolated in 2006-2007 from 22 ICU patients in the Dr A. Jurasz University Hospital in Bydgoszcz. The group included the first $K$. pneumoniae isolates with MBL identified in Poland.

The study included $25 \mathrm{~K}$. pneumoniae strains from 22 ICU patients. Except for four MBLs-positive, the strains were isolated from different patients and various samples: eight $(32,0 \%)$ isolates were from blood and BAL (bronchoalveolar lavage), three were from wound swabs, two were from fistulae swab and urine samples, and single isolates were from the abdominal and peritoneal fluid. All isolates except those from wound and fistulae swabs were recovered as monocultures.

The isolates were identified with commercial ID32E tests (bioMérieux). The antimicrobial susceptibility tests were performed by the disk-diffusion method according to the recommendations of the Polish National Reference Centre for Antimicrobial Susceptibility Testing (Hryniewicz et al., 2006). The

\footnotetext{
* Corresponding author: A. Sękowska, Department of Microbiology, Nicolas Copernicus University, Collegium Medicum in
} Bydgoszcz, Poland; phone: (+48) 52 5853501; e-mail: ala.sek@wp.pl 


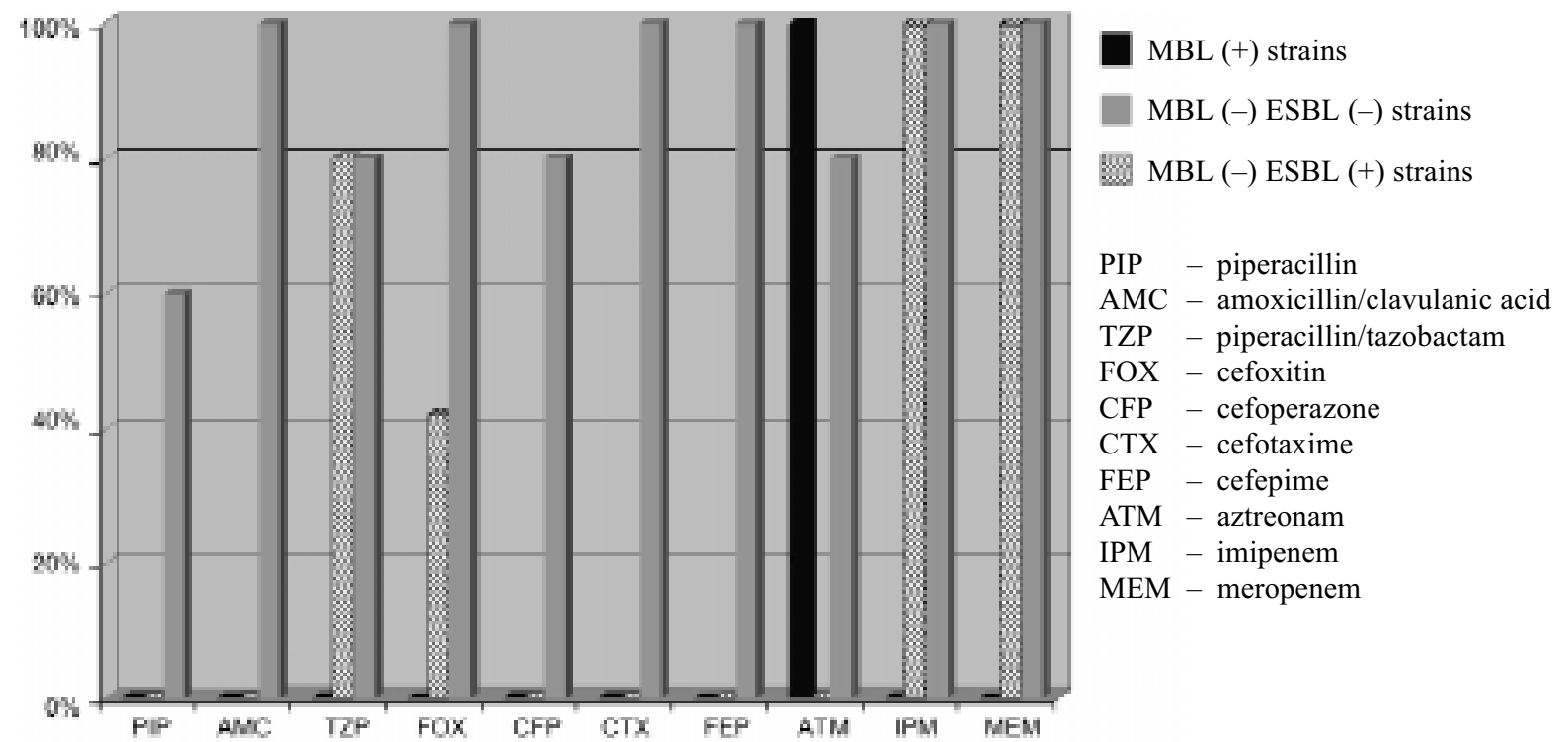

Fig. 1. Sensivity of K. pneumoniae strains to selected beta-lactam antibiotics

presence of ESBLs and MBLs was detected with respective double-disk synergy tests (Arakawa et al., 2000; Jarlier et al., 1988). For all MBL-positive isolates MIC (minimal inhibitory concentration) values of imipenem, meropenem, aztreonam, gentamicin, amikacin, tetracycline and ciprofloxacin were determined with Etest (AB Biodisk) and interpreted due to Clinical Laboratory Standards Institute (CLSI, 2007) recommendations. The presence of MBL genes was tested in an isolate from blood with a commercial kit Hyplex ${ }^{\circledR}$ MBL ID (BAG HEALTH CARE).

According to the results of MBL testing, the study strains were divided into two subgroups: MBL-positive - four strains and MBL-negative - 21 isolates. Among MBL-negative 16 strains were ESBL-producing. The results of antimicrobial susceptibility testing are presented in Fig. 1 and Fig. 2. All strains were resistant to ampicillin. The MBL-producers showed a high-level beta-lactam resistance pattern with resistance to all compounds except for aztreonam. Of the remaining antimicrobials tested, only gentamicin and tetracycline showed in vitro activity against these isolates.

The MBL-positive $K$. pneumoniae isolates were obtained from one patient and were recovered from a wound swab, urine, blood and abdominal fluid. MICs against the MBL-positive isolates were: $>32 \mu \mathrm{g} / \mathrm{ml}$ for imipenem and meropenem, $0.25-0.5 \mu \mathrm{g} / \mathrm{ml}$ for aztreonam, $2-3 \mu \mathrm{g} / \mathrm{ml}$ for gentamicin, $32-64 \mathrm{mg} / \mathrm{ml}$ for amikacin. Tetracycline MICs varied from $0.5 \mu \mathrm{g} / \mathrm{ml}$ to $32 \mu \mathrm{g} / \mathrm{ml}$. Ciprofloxacin MICs were $4-32 \mu \mathrm{g} / \mathrm{ml}$ for isolates from wound swab and abdominal fluid.

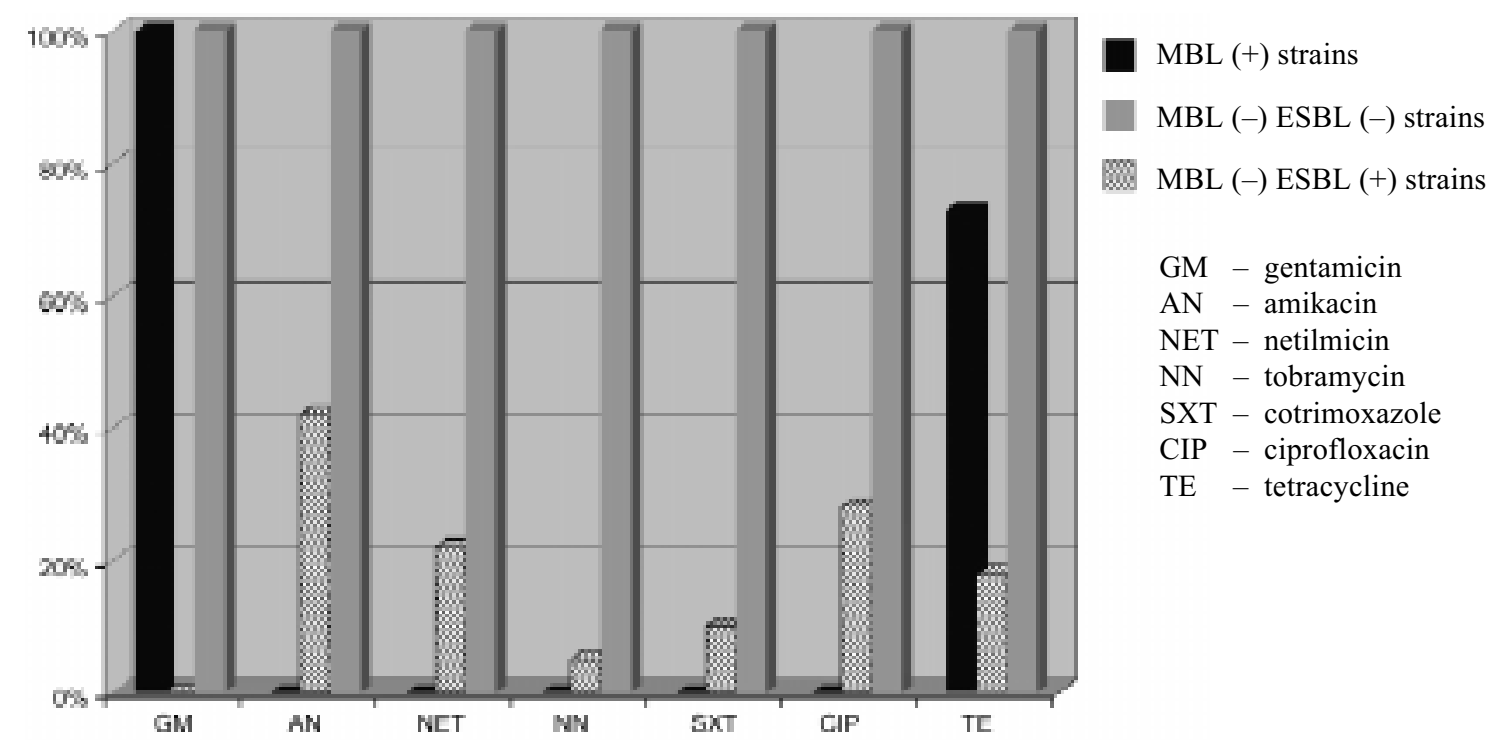

Fig. 2. Sensivity of $K$. pneumoniae strains to selected non-beta-lactam antimicrobials 
The isolate from blood was found to carry a $b a_{\mathrm{VIM}^{-}}$ like family gene, located in a conjugative plasmid (data not shown).

MBL-producing Enterobacteriaceae have been increasingly isolated in recent years (Luzzaro et al., 2004; Toraman et al., 2004; Tórtola et al., 2005; Kassis-Chikhani et al., 2006) especially rapidly disseminating in hospitals in Greece (Giakkoupi et al., 2003; Pournaras et al., 2005). Although MBLs hydrolyze all beta-lactams except for monobactams, enterobacterial isolates with these enzymes relatively frequently appear to be susceptible in vitro to various beta-lactams, including carbapenems (Walsh et al., 2005; Queenan and Bush, 2007). The possibility of their use in such cases, however, has been a controversial issue (Souli et al., 2006). Of note is the highlevel resistance phenotype observed with the MBL producers in our study.

A VIM-type MBL (VIM-1) was first described in a Pseudomonas aeruginosa strain from Verona, Italy, from 1996 (Cornaglia et al., 2000). Currently 12 variants of these enzymes are known and they are divided into three groups: VIM-1-like, VIM-2-like and VIM-7. The VIM-1-like and VIM-2-like enzymes show around $90 \%$ identify at the amino-acid sequence level, and whereas VIM-2-like MBLs have been spreading mostly in $P$. aeruginosa, the VIM-1-like $\beta$-lactamases have been more characteristic for Enterobacteriaceae (Giakkoupi et al., 2003; Pournaras et al., 2005, Walsh et al., 2005). A preliminary further analysis suggested that the enzyme present in our K. pneumoniae isolates belonged to the VIM-1 group as well (data not shown).

To our knowledge, the four MBL producers from a single patient reported here have been the first MBL-positive K. pneumoniae isolates in Poland. Owing to their multi-drug and high-level resistance there have been almost no therapeutic options left. Identification of such organisms in a hospital, even for carriage should be a signal for implementation of the most stringent infection control procedures. Polish clinical microbiology laboratories should start routine testing for MBLs in Enterobacteriaceae.

\section{Acknowledgements}

The authors would like to thank Mr Lars Wassill (AMPLEX DIAGNOSTICSGMBH) and Mr Gerd Heinz (BAG HEALTH CARE) for providing Hyplex ${ }^{\circledR}$ MBL ID (BAG HEALTH CARE).

\section{Literature}

Arakawa Y., N. Shibata, K. Shibayama, H. Kurokawa, T. Yagi, H. Fujiwara and M. Goto. 2000. Convenient test for screening metallo-beta-lactamase-producing gram-negative bacteria by using thiol compounds. J. Clin. Microbiol. 38: 40-43.

Clinical and Laboratory Standards Institute. 2007. Performance Standards for Antimicrobial Susceptibility Testing; Seventeenth Informational Supplement, M100-S17. CLSI, Wayne, PA.
Cornaglia G., A. Mazzariol, L. Lauretti, G.M. Rossolini and R. Fontana. 2000. Hospital outbreak of carbapenem-resistant Pseudomonas aeruginosa producing VIM-1, a novel transferable metallo-â-lactamase. Clin. Infect. Dis. 31: 1119-1125.

Empel J., A. Baraniak, E. Literacka, A. Mrówka, J. Fiett, E. Sadowy, W. Hryniewicz, M. Gniadkowski and the Beta-PL Study Group. 2008. Molecular survey of $\beta$-lactamases conferring resistance to newer $\beta$-lactams in Enterobacteriaceae isolates from Polish hospitals. Antimicrob. Agents Chemother. 52: 2449-2454. Giakkoupi P., A. Xanthaki, M. Kanelopoulou, A. Vlahaki, V. Miriagou, S. Kontou, E. Papafraggas, H. Malamou-Lada, L.S. Tzouvelekis, N.J. Legakis and others. 2003. VIM-1 metallo$\beta$-lactamase-producing Klebsiella pneumoniae strains in Greek hospitals. J. Clin. Microbiol. 41: 3893-3896.

Hryniewicz W., A. Sulikowska, K. Szczypa, A. Skoczyńska, A. Luczak-Kadłubowska and M. Gniadkowski. 2006. Recommendations on antimicrobial susceptibility testing (in Polish). Narodowy Instytut Zdrowia Publicznego. Warsaw. Poland

JarlierV., M. Nicolas, G. Fournier and A. Philippon. 1988. Extended broad-spectrum $\beta$-lactamases conffering transferable resistance to newer $\beta$-lactam agents in Enterobacteriaceae: hospital prevalence and susceptibility patterns. Rev. Infect. Dis. 10: 867-878.

Kassis-Chikhani N., D. Decré, V. Gautier, B. Burghoffer, F. Saliba, D. Mathieu, D. Samuel, D. Casting, J.C. Petit, E. Dussaix and others. 2006. First outbreak of multidug-resistant Klebsiella pneumoniae carrying blaVIM-1 and blaSHV-5 in a French university hospital. J. Antimicrob. Chemother. 57: 142-145.

Livermore D.M. 2008. Defining an extended-spectrum- $\beta$-lactamase. Clin. Microbiol. Infect. 14: 3-10.

Luzzaro F., J.D. Docquier, C. Colinon, A. Endimiani, G. Lombardi, G. Amicosante, G.M. Rossolini and A. Toniolo. 2004. Emergence in Klebsiella pneumoniae and Enterobacter cloacae clinical isolates of the VIM- 4 metallo- $\beta$-lactamase encoded by a conjugative plasmid. Antimicrob. Agents Chemother. 48: 648-650. Pournaras S., A. Ikonomidis, L.S. Tzouvelekis, D. Tokatlidou, N. Spanakis, A.N. Maniatis, N.J. Legakis and A. Tsakris. 2005. VIM-12 a novel plasmid mediated metallo- $\beta$-lactamase from Klebsiella pneumoniae that resembles a VIM-1/VIM-2 hybrid. Antimicrob. Agents Chemother. 49: 5153-5156.

Queenan A.M. and K. Bush. 2007. Carbapenemases: the versatile $\beta$-lactamases. Clin. Microb. Rev. 20: 440-458.

Rudnicka J., M. Wróblewska, H. Marchel and M. Luczak. 2005. Comparison of frequency and susceptibility to antimicrobials of bacterial strains of the family Enterobacteriaceae isolated from patients hospitalised in intensive care units (in Polish). Med. Dośw. Mikrobiol. 57: 185-191.

Souli M., Kontopidou F.V., Koratzanis E., Antoniadou A., Giannitsioti M., Kopoulou P., Kannavaki S. and H. Giamarellou. 2006. In vitro activity of tigecycline against multiple-drug-resistant including pan-resistant Gram-negative and Gram-positive clinical isolates from Greek hospitals. Antimicrob. Agents Chemother. 50: 3166-3169.

Toraman Z.A., Y. Yakupogullari and A. Kizirgil. 2004. Detection of metallo $\beta$-lactamase production and antibiotic resistance with E-test method in pseudomonas, acinetobacter and klebsiella strains, in Turkey. J. Infect. Chemother. 10: 257-261.

Türtola M.T., S. Lavilla, E. Mirü, J.J. González, N. Larrosa, M. Sabaté M, F. Navarro and G. Prats. 2005. First detection of a carbapenem-hydrolysing metalloenzyme in two Enterobacteriaceae isolates in Spain. Antimicrob. Agents Chemother. 49: 3492-3494.

Watanabe M., S. Iyobe and M. Inoue. 1991. Transferable imipenem resistance in Pseudomonas aeruginosa. Antimicrob. Agents Chemother. 35: 147-151.

Walsh T.R., M.A. Toleman, L. Poirel and P. Nordmann. 2005. Metallo-beta-lactamases: the quiet before the storm? Clin. Microb. Rev. 18: 306-325. 